\title{
Grace and Free Will: Quiescence and Control
}

\author{
Simon Kittle \\ University of Sheffield
}

\begin{abstract}
Stump and Timpe have recently proposed Thomistic based solutions to the traditional problem in Christian theology of how to relate grace and free will. By taking a closer look at the notion of control, I subject Timpe's account - itself an extension of Stump's account - to extended critique. I argue that the centrepiece of Timpe's solution, his reliance on Dowe's notion of quasi-causation, is of no help in addressing the problem. As a result, Timpe's account fails to avoid Semi-Pelagianism. I canvass two alternatives, each of which adheres to the broad theological assumptions made by Stump and Timpe. I conclude that both proposals fail, although I argue that one comes as close as it is possible to get to a solution given the assumptions made.
\end{abstract}

\section{Introduction}

There is a long standing problem in Christian theology which can be generated with two thoughts central to Christian thinking. The first is that people are responsible for failing to come to faith in Christ and the second is that saving faith is entirely a gift from God, a gift that is not earned nor given based on any merit. If one accepts the view that responsibility requires free will, then the first claim implies that the person is to some degree active in coming to faith - it is something that the person does, and does freely. The second claim was originally made against the Pelagians and Semi-Pelagians. ${ }^{1}$ Roughly, the Pelagians denied that the Fall damaged the moral capacities of humans and affirmed that post-Fall humans had the power to do all that was required of them by God's commandments (including turning to God). The Semi-Pelagians denied this, but they did insist that fallen humans could at least begin or try to seek after God. The second claim is the denial of these ideas: it affirms that God is the sole actor in the process of a human coming to faith. This implies that the person is passive in a way which is in tension with the first claim. Eleonore Stump has recently presented a Thomistic solution to this traditional theological problem. Her account has been criticised by Kevin Timpe, who has suggested how the account might be extended to meet the problem. Here I argue that Timpe's account is unsuccessful in avoiding Semi-Pelagianism. I canvass two possible ways forward, suggesting that one fails outright and the other has partial success if one understands the condemnations of the (Semi-)Pelagians in

${ }^{1}$ For some useful background see Pohle (1917a; 1917b).

Journal of Analytic Theology, Vol. 3, May 2015 10.12978/jat.2015-3.180813100804

(C)2015 Simon Kittle • (C) 2015 Journal of Analytic Theology 
a particular manner. This partial solution, however, has some untoward consequences.

\section{Stump's solution and its flaw}

Stump has recently claimed that Aquinas's theory of the human will provides a way to reconcile the two claims outlined above (Stump 2003, 389-404). The key is to recognise that the human will has not just two "positions" but three: with respect to some issue, the human will can assent to it, reject it, or be in a state of quiescence. In this latter state the will is neutral with respect to the issue at hand it is simply "turned off" (Stump 2003, 394). This promises a solution along the following lines: God is constantly offering grace to everyone (Stump 2007, 103). The default state of normal, post-Fall human beings is to resist this offer; moreover, such post-Fall humans are unable to accept it. However, people in this state can become quiescent with respect to God's offer of grace. That is, they can move to a state of neither accepting God's grace nor rejecting God's grace. Once the person is in this state of quiescence, God infuses grace into that person. This infusion of grace reconfigures the person's will and enables her to assent to loving God. But the assent only comes after God has operated on the agent's will.

According to Stump's Thomistic account of the will there are a number of ways that an agent might become quiescent with respect to some issue. The one that is relevant to the issue of grace and free will, however, concerns the agent's intellect. An agent moves to a state of quiescence with respect to some issue when there is a conflict in her intellect on that issue such that the agent is unable to form a "single, integrated judgement about it" (Stump 2003, 399). Being unable to form a judgement about what is best with respect to the topic at issue, the person is said to abstain from judgement. The result is a state of quiescence: the agent neither affirms the thing nor rejects the thing.

On this account nothing external to the agent causes the state of quiescence: the quiescence is due ultimately to the operation of the person's intellect and this, Stump argues, secures the person's control over, and responsibility for, whether or not she fails to come to faith (Stump 2003, 401). However, the process of becoming quiescent is not something the agent does - it is not an action. After all, to stop doing something (e.g. resisting grace) need not mean the performance of some further action (e.g. accepting grace) (Stump 2003, 402). The agent who stops resisting grace is simply doing nothing, i.e., she is in a state of quiescence. Moreover, Stump concludes that because the state of quiescence is not a positive state but a lack - the agent's will, having ceased resisting God, isn't doing anything else (like accepting God) instead - the person still does not possess a good will. This means that the person neither performs a good action nor possesses a good will and so the account avoids both Pelagianism and Semi-Pelagianism.

C. P. Ragland (2006) and Timpe (2007) have both raised a problem for Stump's account, namely, that her account does not secure for the human person enough control over the process of becoming quiescent and, ultimately, over her 
coming to saving faith. On the Thomistic view that Stump endorses, "whether the will is turned off or not is always in the power of the will itself" (Stump 2003, 394). Despite this, however, Stump says that the process of becoming quiescent is not itself an action. As mentioned above, a person becomes quiescent when her intellect enters a state of conflict which it cannot resolve - the intellect cannot produce a "single, integrated judgement" about what is best. This indecision in the intellect produces inactivity in the will (Stump 2003, 399).

On this account it is true that the ultimate source of the agent's quiescence is in the agent herself. This can be so because we can suppose that the operations of the intellect and will are indeterministic, such that the resulting state of quiescence cannot trace its origin back to something external to the agent. It is indeed the case then, as Stump says, that only the agent's "own intellect and will that determine which position her will is in" (Stump 2003, 402). The problem is that this is not enough for control. Ragland puts the worry like this $(2006, \S 5)$ :

To avoid slipping into Semi-Pelagianism, Stump is forced to represent humans as altogether too passive with respect to whether they become quiescent: quiescence is not a state that they actively choose, but is rather a kind of paralysis of intellect and will that befalls humans.

Many states of an agent, including psychological states, might be indeterministically caused by other states or events internal to the agent, and yet not under the agent's control. Ragland gives the example of an evil thought that pops into one's mind unbidden: "we have control over whether or not to consent to such a thought or to dwell on it, and we might have control over its recurrence ... but we don't have control over the initial occurrence of the thought" $(2006, \S 5)$. That is so even if the occurrence of the evil thought is not deterministically caused, and traceable only to states or events internal to the agent. Examples are not limited to moral contexts. Emotional or physical events or states internal to the agent might cause in the agent a further event or state over which the agent has no control: an involuntary twitch in a person's muscle might cause her to shuffle in her seat, a general feeling of fear might result in a person walking home more quickly, and so on. The point is that although the ultimate source of the agent's quiescence is internal to the agent, this does nothing to produce control over the event or state. And this point seems decisive. While it's plausible to think this kind of sourcehood is a necessary condition on something's being under the agent's control, it is not a sufficient condition. The very thing, then, that Stump rules out in order to avoid (SemiJPelagianism - there being a prior act of will - undermines her claim that the agent has the right kind of control which is capable of securing her responsibility.

\section{Timpe's proposed solution}

Timpe thinks that Stump's account can be augmented so as to address the worry just outlined. What we need, he says, is "an account ... which can maintain 
both that grace is the sole non-instrumental efficient cause of saving faith and that human agents control whether or not they come to saving faith" (Timpe 2007, 289). In addressing the problem Timpe outlines a constraint which he thinks any account aiming to stick to traditional orthodoxy should aim to satisfy:

(Anti-Pelagian Constraint) No fallen human individual is able to cause or will any good, including the will of her coming to saving faith, apart from a unique grace (Timpe 2007, 285).

Timpe employs a strong reading of the Anti-Pelagian Constraint which precludes the agent being $a$ cause (as opposed to the sole cause) of her coming to saving faith. According to Timpe, if this constraint can be satisfied we will have an account which is neither Pelagian nor Semi-Pelagian.

To provide this account Timpe takes a closer look at the state of quiescence. He thinks that Stump is on the right lines when she notes that an agent's state of quiescence is not a positive thing - it is rather an absence or omission. Indeed, Timpe argues that this provides the key to the solution because (on at least some dominant theories) omissions cannot be causes. This means quiescence so conceived would not count as a cause. But because, on these same accounts, omissions can enter into causal explanations they might nevertheless be able to ground the agent's control over (and so responsibility for) her lack of faith.

To develop this idea Timpe appeals to Dowe's account of "causation" of and by omissions. Dowe accepts the view that omissions, because they are absences, are not genuine causes. But they can be cited in causal explanations, and because of this we can treat them as "quasi-causes" $(2001,217)$. Dowe's account has two parts: first, quasi-causation by an omission $(2001,222)$ :

(Quasi-causation by omission) An omission (not- $A$ ) is the quasi-cause of some event $B$ if $B$ occurred and $A$ did not, and there occurred an $x$ such that

(01) $x$ caused $B$, and

(01) had $A$ occurred, then $A$ would have prevented $B$ from occurring by interacting with $x$.

Second, the quasi-causation of omissions, otherwise known as prevention (Dowe 2001, 221):

(Quasi-causation of omissions) $A$ quasi-caused not- $B$ if $A$ occurred and $B$ did not, and there occurred an $x$ such that

(P1) there is a causal interaction between $A$ and the process due to $\mathrm{x}$, and

(P2) if $A$ had not occurred, $x$ would have caused $B$.

How does this help with the issue of control? Timpe's idea is that being able to quasi-cause an omission bestows on the agent control over that omission. This idea is motivated by the following kind of example (which comes from Dowe): suppose that a child is about to run out into the street and his father grabs him just at the last minute. The father's grabbing the child prevented an accident. In terms of the 
accounts above: the father's grabbing the child quasi-caused the lack of an accident because there was a process $\mathrm{x}$ - the child's running about - which the father interfered with, and which was such that had the father not interfered with it, the process would have caused an accident. Thus, the father has control over whether or not there was an accident even though, if there had been an accident, the father would not have caused the accident.

Timpe thus suggests the following view of control (Timpe 2007, 292):

An agent controls an event $e$ when either

(1) an action of the agent causes $e$ to occur, or

(2) an omission by that agent quasi-causes $e$ to occur.

Timpe thinks that this allows us to develop an account according to which only God's grace is causally efficacious but which puts the individual in control of whether or not they come to saving faith. His account has two components. First, individuals quasi-cause their being quiescent with respect to God's offer of grace by an act of will (i.e. we first have an instance of the quasi-causing of an omission). This positive act of will quasi-causes (as opposed to causes) the agent's quiescence because quiescence is an omission. The act of will interferes with a process - the agent's natural disposition to resist God - which is such that had it not been interfered with, it would have produced the state of resisting God. Thus we can say that the act of will quasi-causes the lack of the will's resisting God, or in other words, the agent's state of quiescence. It is the positing of this act of will which clearly distinguishes Timpe's account from Stump's: Stump wanted to avoid positing an act of will because she thought it would mean that the agent could take credit for their coming to saving faith. Timpe thinks this can be avoided once we recognise the role that quasi-causation is playing here. ${ }^{2}$

The second step of his account is the quasi-causing of the act of saving faith by the individual's state of quiescence. Here we have a case of quasi-causation (as opposed to causation), not because an omission is being produced, but because the omission is leading to something (so Timpe's second step involves quasi-causation by an omission). The state of quiescence quasi-causes the agent's coming to saving faith because there was a process - God's acting on (reconfiguring of) the will of the agent - which resulted in the agent's saving faith, but which was such that, had the agent not been quiescent, the process would not have succeeded. The two instances of quasi-causation mean that the agent has control over whether or not she comes

\footnotetext{
${ }^{2}$ Given the centrality of this act of will to Timpe's account it is natural to ask what the content of this act of will is. Timpe characterises it only as "an act of will through which [the agent] becomes quiescent" (Timpe 2007, 294). There are serious questions to be asked about whether such an act of will is possible. After all, we cannot simply will ourselves to be in any state we wish. If I'm anxious about an upcoming event, it's unlikely that I can simply will myself into a state of contentment. If I'm sitting in front of a blue car I cannot simply will myself to see a red car; I could decide to bring it about that I see a red car, but that would involve more than willing - it would involve getting up and searching for such a car. There is then a very real threat looming for Timpe's account. I will not push this threat, however, and will grant that there is such an act of will Timpe may appeal to.
} 
to saving faith. Even so, on this account it is God alone who is causally efficacious in the individual's coming to faith, and this, Timpe thinks, means that his account is in no way Pelagian or Semi-Pelagian (Timpe 2007, 293-94).

\section{Control and agency}

\subsection{Timpe's account of control: problems and repairs}

In what follows I will argue that Timpe's account fails to avoid SemiPelagianism, even though his account may well satisfy his Anti-Pelagian Constraint. The following is a brief overview of my argument. First, I will suggest that Timpe's account of control is inadequate. It is too broad (on a number of counts), affirming, for example, that agents control all kinds of things even when they are asleep. The account is fixable, I will suggest, but once we make the required fixes then it will become clear that we have control only when we have an instance of "full-blooded" human agency. That is, Timpe is right to suggest that control can be exercised via quasi-causation, but that is only because agency itself can be transmitted via quasicausation. Once we're clear, however, that we have an instance of agency with respect to the person's coming to saving faith, then it will not be at all clear why we should deny that the agent is able to bring about her coming to saving faith.

This point leads us to a deficiency with Timpe's Anti-Pelagian Constraint: it does not cover the entire range of human agency. It affirms that the agent cannot positively cause something which will lead to her salvation ('cause' being used in the technical sense in which it stands opposed to quasi-causation), and also that the agent cannot positively will his coming to saving faith ('will' being used in a technical sense where it refers to the active forming of an intention to accept grace directly), but it does not preclude the agent's being able to (intentionally) bring it about that she comes to saving faith in a different way, namely, by acting in a way which involves quasi-causation.

The Anti-Pelagian Constraint should, of course, preclude the agent's being able to bring about her salvation however that is done. Just as it is absurd to think that those who condemned (Semi-)Pelagianism meant to exclude the possibility of an agent being able to directly will her salvation whilst allowing that an agent might be able to bring herself to saving faith by, say, tapping an orange three times whilst crouching, so too it is absurd to think that those who condemned (SemiJPelagianism meant to exclude the possibility of the agent positively willing her salvation whilst allowing that an agent might be able to bring herself to saving faith by an action involving quasi-causation. I will close this section by addressing various objections, some of which were offered by Timpe in response to points similar to those I'm raising here.

To begin, recall Timpe's account of control:

An agent controls an event e when either

(1) an action of the agent causes e to occur, or 
(2) an omission by that agent quasi-causes e to occur.

The first point I want to make is that clause (2) is too broad. Timpe has adopted Dowe's theory of causation which makes a distinction between causation, which applies only to positive events, and quasi-causation, which may involve omissions. In Dowe's theory, an omission is a lack or absence. The term 'omission' implies no sense of agency. Let's be clear about what this means: right now there is no one in my study. Given this, my lack of being in the study is, according to Timpe, quasicausing my study to be at its uninhabited temperature. Moreover, your absence from my study is also quasi-causing it to be at its uninhabited temperature. Indeed, every single person on the planet is quasi-causing my study to be at its uninhabited temperature. Quasi-causation is, to understate the issue, abundant. Every human agent quasi-causes all sorts of things, and not just when awake and active but also when asleep.

It's plausible to think that, in my case, right now, there might be a sense in which I omitted to be in my study; that is, my omission might be an instance of my agency. For example, it might be that I consciously decided to go and sit in the living room instead of the study. If that is the case then I refrained from sitting in my study and my omission is imputable to me as something I did. But this will not be plausible for anyone but me. And we must be clear: even though some omissions are instances of agency in this stronger sense, Timpe's account is not employing this stronger sense. It is employing the notion of a mere lack or absence. No agency is implied. And for this reason, it should be doubted that quasi-causation suffices for control. While my quasi-causing my study to be at its uninhabited temperature might, in the manner just outlined, be something that is imputable to me, that will not be plausible for anyone else. Your quasi-causing my study to be at its uninhabited temperature is not an exercise of your agency - you haven't exercised control over the temperature of my study.

If it isn't yet obvious that quasi-causation is not sufficient for control, note that Timpe's first clause does involve an instance of agency. An agent controls an event if it is caused by one of the agent's actions. So with respect to positive causation, Timpe thinks that in order for there to be control, there has to be an action, an instance of agency. We might wonder why there is no symmetry here. If Timpe doesn't think we need an instance of agency to have control with respect to omissions, why does he think we need one when it comes to positive causation? Why not say that an agent controls an event whenever she causes it to happen, regardless of whether she acts? After all, if an agent exercises control over the temperature of my study in virtue of quasi-causing its uninhabited temperature, which would be the case when that person is, say, asleep and on the other side of the world, doesn't someone who is currently asleep in some room, such that she is causing (and not just quasi-causing) its temperature to be slightly higher than it would otherwise be, exert at least as much control over the room's temperature? Timpe's account, I take it, is better revised in the other direction: rather than diluting clause (1) we should strengthen clause (2). Not any old instance of quasicausation is enough for control; rather, just those cases of quasi-causation where the omission counts as a refraining, as a genuine instance of agency. Anyone who 
agrees that the person sleeping on the other side of the world is not exercising control over the temperature of my study will be led to amend clause (2) in this way. If Timpe resists this move, and insists that quasi-causation without agency is enough for control, then we need an account of why this kind of "control" deserves the name, for ordinarily we do not think one thing's causing (or quasi-causing) another counts as control. I will assume, then, the clause (2) needs to be revised to focus on just those omissions which are instances of agency, although I will not attempt to delineate the conditions under which that is so.

Why would making this revision be problematic for Timpe? The point threatens to undermine the basis for his solution. Timpe distinguishes two ways that an agent might control an event: either by causation or by quasi-causation. And this distinction is central to his solution. When someone controls something via quasi-causation, Timpe thinks that that instance of controlling need not be subject to the Anti-Pelagian Constraint. But why is this? As we've just seen, the agent controls something via quasi-causation only when she acts, only when the omission is an instance of the person's agency. But if that is so, why think instances of agency which involve quasi-causation should be excluded from the Anti-Pelagian Constraint? After all, we ordinarily say that agents are able to do the things which they can do via quasi-causation. Moreover, it's clear that agents can bear responsibility both for acting in a way which involves quasi-causation and for the associated omissions.

Consider some examples. I see someone slowly reversing out of a driveway who is about to run over his puppy. Having a strong dislike of dogs, I deliberately refrain from signalling the driver, who subsequently runs over the puppy. According to Dowe I quasi-cause the puppy's death for there was a process - the driver's slowly reversing his car - which eventually caused the puppy's death and which was such that, had I interrupted it by signalling the driver, would not have done so. I deserve (at least some) blame both for not signalling the driver and for the puppy's death, and this is so even though I "only" quasi-caused the puppy's death. Note that on Dowe's theory you too quasi-caused the puppy's death because you too omitted to signal the driver. Indeed, everyone quasi-caused the puppy's death. Yet you are not responsible for your omission nor the puppy's death: they are not imputable to you, because your omission was not an instance of agency in the way my omission was. Still, despite my agency involving quasi-causation, the result is imputable to me and I bear responsibility for it. This provides an example of an agent being blameworthy for the quasi-causing of an event by an omission.

People can also be praiseworthy for quasi-causing something by an omission: suppose that Jim is holding forth on some topic and utters some untruth; Kim knows this, but recognising that little harm will come of it, refrains from pointing out his error, thus saving Jim much embarrassment. Kim's omission - her not saying anything - quasi-causes Jim's lack of embarrassment. And Kim is praiseworthy both for her omitting to say anything and for Jim's lack of embarrassment.

Similar things apply to the quasi-causation of omissions. We've already encountered Dowe's example of the father who, in grabbing his child before the child runs into the road, prevents an accident. The father's grabbing the child quasicauses the lack of an accident because there was a process - the child's running into 
the road - which would have caused an accident had the father not grabbed him. The father is praiseworthy for his action but also for there not being an accident. That is, he's praiseworthy for there being no accident. And we can easily imagine a situation involving blameworthiness. Suppose that the child is running about as part of a two-player game of tag. The father grabs his child, removing him from the game, and so quasi-causes the lack of there being any game. Under the right circumstances, the father might be blameworthy for the absence of there being a game. Thus we have examples of an agents being praiseworthy and blameworthy for both the quasi-causing of an event by an omission and for the quasi-causing of an omission by an event. In each case we have a "full-blooded" instance of agency; in each case the agent bears the same kind of moral responsibility that he or she would bear had the action involved only causation.

But these instances of agency are excluded from Timpe's Anti-Pelagian Constraint which, recall, runs as follows:

(Anti-Pelagian Constraint) No fallen human individual is able to cause or will any good, including the will of her coming to saving faith, apart from a unique grace.

This constraint says that agents are unable to come to saving faith by causing or willing anything good. The term 'cause' here should be read in the technical sense that Timpe employs. And of course, Timpe is free to formulate the constraint using a technical sense of the term 'cause.' But if he does so, then the question must be faced: what justifies the exclusion of those things that people do via quasicausation? After all, it certainly seems as if such people are able to do those things. I, for example, was able to bring about the puppy's death; Kim was able to save Jim from embarrassment; the father was able to prevent the accident, and so on. So the ordinary language use of 'able' covers things done both via causation and via quasicausation. And as we saw, the agents bore full responsibility for the things they did. If, therefore, the intent behind the condemnation of the (Semi-)Pelagians was to say that agents were not able to do any salutary work no matter how it was done Timpe's account will be in trouble - not because it fails to satisfy the Anti-Pelagian Constraint but rather because the Anti-Pelagian Constraint isn't what needs to be satisfied. And there is good reason for thinking this is what they did intend. Consider canon 4 from the 418 A. D. Council of Carthage (the first major council to condemn Pelagianism):

Whoever shall say that the grace of God through Jesus Christ our Lord helps us only in not sinning by revealing to us and opening to our understanding the commandments, so that we may know what to seek, what we ought to avoid, and also that we should love to do so, but that through it we are not helped so that we are able to do what we know we should do, let him be anathema (Schaff, 497-98).

This canon discusses what we are able (or rather, unable) to do and appears to be precluding the ability to do those things that we should do. We've already seen that 
ordinary language allows use of 'able' when referring to things we do which involve omissions. Note too that this canon explicitly mentions things we ought to avoid things which on Timpe's account will necessarily involve quasi-causation. If God's grace is needed to avoid those things we should avoid, then the Anti-Pelagian Constraint should cover instances of agency involving quasi-causation. Similarly, canons 6 and 7 of the Second Synod of Orange (the major pronouncement condemning Semi-Pelagianism) say:

(Canon 6) If anyone says that God has mercy upon us when, apart from his grace, we believe, will, desire, strive, labor, pray, watch, study, seek, ask, or knock, but does not confess that it is by the infusion and inspiration of the Holy Spirit within us that we have the faith, the will, or the strength to do all these things as we ought ... he contradicts the Apostle.

(Canon 7) If anyone affirms that we can form any right opinion or make any right choice which relates to the salvation of eternal life ... or that we can be saved, that is, assent to the preaching of the gospel through our natural powers without the illumination and inspiration of the Holy Spirit ... he is led astray by a heretical spirit.

Again the thought is that human agents cannot do any salutary work apart from a special gift of grace from God. But it's not as if the pronouncements say "you cannot will the good by causing such a volition in yourself, although you may bring it about that you come to saving faith by quasi-causing in yourself a state of quiescence." Nothing is being said about the different kinds of human action - rather, a blanket denial is being made. In other words, it is irrelevant to the pronouncements of the councils what the correct metaphysics and causal structure of human action is: if such a metaphysics involves quasi-causation, then quasi-causation is precluded.

This point can be brought home by highlighting that quasi-causation is not implicated in only those instances of agency which obviously involve omissions, and which we typically describe negatively. As Schaffer has pointed out, because of the way our muscles work - they contract when two components of muscle cells bind together, which by default is inhibited from happening, but which does happen when an electrical impulse from the nervous system quasi-causes a lack of the relevant inhibitor - most if not all human action involves quasi-causation (Schaffer 2012, 407). Certainly, when we "strive, labor, pray, study, seek, ask or knock," we act in ways which involve quasi-causation.

The basic problem, then, is that the Anti-Pelagian Constraint doesn't exclude enough because it doesn't exclude from the range of things fallen agents can do those omissions which count as instances of agency. There are two ways to press this point. First, quasi-causation appears to be implicated in many human actions that are usually described in positive terms and which would therefore be excluded by the Anti-Pelagian Constraint. But if the Anti-Pelagian Constraint is already excluding some actions which involve quasi-causation, the exclusion of other actions involving quasi-causation appears unmotivated. Second, as I've suggested above, it's clear that many omissions are "full-blooded" instances of human agency. They 
are things that are imputable to the agent, and things for which the agent is responsible. There is therefore every reason to think that if an agent comes to saving faith via becoming quiescent, her coming to saving faith should, to at least some degree, be attributable to her. And to the degree that she was involved in bringing it about, she will be praiseworthy.

\subsection{Objections and replies}

What might Timpe say in response to the above? Timpe envisages and addresses a number of complaints that are similar to the issues raised above, and it will be instructive to consider them now. His most pertinent set of responses comes in reply to the following objection:

Suppose that what is most important about the [Anti-Pelagian Constraint] ... is that the agent not be able to take credit for her own salvation. ... But agents can be praised and blamed for the omissions when brought about by their own acts of will, whether or not one wants to bring such cases under the rubric of quasi-causation. So it's not clear, even if [the Anti-Pelagian Constraint] is 'technically' satisfied, ... that it isn't violated in a more important sense (Timpe 2007, n. 49).

Timpe's discussion of this point is brief, the objection and his response appearing only in a footnote, but we may extract three claims that might be designed to address the issue (Timpe 2007, n. 49):

(a) “One doesn't deserve credit for one's becoming quiescent precisely because quiescence isn't a positive or good act of the will - it is instead a lack of an act of will."

(b) The prior act of will to become quiescent is distinct from willing to accept grace.

(c) While willing to accept grace is a good act and something for which the agent would deserve credit, willing to become quiescent is not a good act. It is a better act than willing to resist grace, but being better does not make it good. Thus, willing to become quiescent is not something for which the agent can take credit.

Consider point (a). I take it that Timpe intends the phrase 'one's becoming quiescent' to refer to the action - the prior act of will - which leads to the agent's state of quiescence. Reading the phrase like this - as opposed to reading it as referring to the resulting state - is supported by Timpe's treatment of the agent's responsibility for the resultant state later on in the footnote (extracted here as point (c)). So the idea is that the agent doesn't bear responsibility for this action "precisely because quiescence isn't a positive or good act of the will - it is instead a lack of an act of will." 
Is Timpe's emphasis here on quiescence not being a good act of will, or is the emphasis on the fact that quiescence is a lack? The two are to some degree related: quiescence cannot be a good act of will if it is no act of will at all. Timpe is right about that much. Suppose the focus is on quiescence not being a good act of will doesn't that mean that the agent deserves no credit here, for surely "one cannot deserve credit for X if X is not a morally good action"? ${ }^{3}$ The principle that a person cannot deserve credit for $X$ if $X$ is not a morally good action may be challenged if 'good' here is understood as a matter of value - moral goodness or badness - as opposed to moral rightness or wrongness. To anticipate something that I will elaborate on below, plausibly, the rightness or wrongness of an action depends on the range of options available. If an agent has two options available, neither of which has much value (i.e. neither of which is morally good), still the agent might do the right thing - and so deserve credit - if she brings about the better of the two. The crucial point for present purposes is that the action Timpe's opponent is pointing to here is not the agent's quiescence (which isn't even an action) but the agent's becoming quiescent. And the latter may be an action for which the agent deserves moral praise even if the resulting state is not intrinsically good.

Perhaps, then, Timpe's focus is on the fact that quiescence is a lack or absence. It's not entirely clear how this thought is to be developed. One possibility is that in order to be responsible for an action which is essentially characterised in terms of an absence, one would have to think that there is such an absence. That is, one would have to reify the absence. This, it might be thought, is too high a metaphysical price to pay.

Not only are we not given any reason for thinking this (or even any reason for thinking this is what Timpe has in mind), the position is implausible. We can make sense of the agent's responsibility for her act of will and her responsibility for her quiescence (an absence) without reifying absences. Her act of will to become quiescent is an action that cannot be understood apart from the lack of a certain state, but this can be explained in terms of states of affairs: what the agent intends to do is bring about a certain state of affairs, one characterisable only negatively. Moreover, we can say, without reifying absences, that the agent is responsible for the fact that she is quiescent. So it is unproblematic to think of the agent as responsible for the action by which she becomes quiescent and for the resulting state of quiescence.

There is nothing unusual or mysterious about this. When I forget to water a neighbour's plant I'm responsible, not for some strange negative entity, but rather for the fact that the plant died. If I promise to get milk on the way home but forget I'm responsible for the subsequent lack of any milk in my kitchen. This doesn't require that there be a strange 'non-milk' object in my kitchen. I'm simply responsible for the fact that there is no milk in my kitchen. The father who grabs his child in time is responsible for the fact that there was no accident. Similarly, when the agent wills to become quiescent she is responsible for the fact that she is now in a state of quiescence. So this first reply fails to gain any traction.

${ }^{3}$ I thank an anonymous referee for pushing this point. 
Now consider point (b). Timpe argues that the act of will to become quiescent is distinct from the willing to accept grace. Timpe needs to affirm this in order to avoid having to say that the agent's willing to become quiescent is good. If willing to become quiescent just is willing to accept grace, then it would be hard to deny that the former is good because the latter is clearly a good act.

With respect to this point, it is important to be clear about what we're referring to. I take it that as used by Timpe, the act of will is understood as something like the agent's active forming of a first-order volition with the content that I become quiescent (or something similar). Likewise, the agent's act of will to accept God's grace is to be thought of as the agent's active forming of a first-order volition with the content that I accept God's grace (this latter is, of course, something the agent cannot do). Conceived of like so, Timpe's point is straightforward: the two actions are distinct.

But that is not the end of the story, for human agents are able to - indeed, they often have to - do one thing by doing another thing. This opens up the possibility that the agent might bring it about that she accepts grace by willing to become quiescent. Consider the following example which I think makes the point easier to grasp:

(Arm raising) My right arm is attached to a hoist which is capable of lifting it up. The hoist is mechanically operated by a handle which I can turn with my left hand. I know how to use the hoist.

Given this setup there are two ways I can raise my right arm. I can raise it in the normal way or I can raise it by turning the handle of the hoist. When I raise my hand in the normal way I form a first-order intention to raise my hand in an unmediated way: I will that I raise my arm ("directly"). This corresponds to the person's actively forming a first-order volition to accept God's offer of grace. But there is a second way I can raise my arm: I can use the hoist. Now suppose I'm operating the machine and someone comes in and asks me what I'm doing. I could say, 'I'm hoisting my arm up,' but I could also say (equally correctly) 'I'm raising my arm' and 'I'm bringing it about that my arm is raised.'

Now the Arm raising story is not quite parallel to the process of coming to faith as envisaged by Timpe because in Arm raising I have both routes available to me: I can raise my arm in the normal way, or I can use the hoist. Suppose, however, that my right arm is paralysed. I cannot raise my right arm "in the normal way." We could suppose too that I have some strange phobia that precludes me from even willing to raise my right arm: that is, I cannot actively form a first-order intention with the content that I raise my right arm (in the unmediated way). Still, I can raise my arm. I can do it using the non-standard method of hoisting it up by operating the machine with my left arm. And in that case, all the statements above are still true of me: I'm raising my arm, I'm bringing it about that I raise my arm, I'm intending to raise my arm, and I'm willing that I raise my arm. ${ }^{4}$

\footnotetext{
${ }^{4}$ Leigh Vicens has suggested that this example would not carry as much force if the machine were replaced by a person. For example, suppose that instead of pushing a button I had to ask a person to
} 
Similar things are true of the person who cannot actively form a first-order volition to accept God's grace. If that person knows that were she to become quiescent God would infuse grace into her and she would come to saving faith, then she has a means by which she can bring it about that she comes to saving faith. So when she wills to become quiescent, she also brings it about that she acquires saving faith.

Finally we come to (c). Timpe argues that the agent does not deserve any credit for willing to become quiescent because, although willing to be quiescent is better than willing to resisting God, it is still not good. Better does not make good. Thus, he is under no pressure to concede that the agent deserves any credit on the basis that she willed to be quiescent. Timpe offers an analogy to support this idea:

Suppose that Joe has the opportunity to steal $\$ 100$ from his boss, but steals instead only $\$ 20$. Joe's action here is better than it could have been, but this does not mean that Joe deserves any sort of moral credit for the action that he did do.

I agree that, on the most natural interpretation of this case, Joe does not deserve credit for only stealing $\$ 20$. But notice a crucial difference: in the Joe story we ordinarily assume that Joe has other options available. We assume that Joe could refrain from stealing altogether. The availability of this options makes the cases disanalogous because with respect to coming to saving faith the agent has no other options. We could bring Timpe's example more into line with the quiescence case by attempting to remove the possibility of the agent's refraining altogether from stealing. Suppose, for example, that Joe is subject to the following threat: if he does not steal from his boss, his whole extended family and all his friends will be killed. In addition, let's say that at one end of his boss's table lies a crisp twenty dollar bill, at the other end lies a one hundred dollar bill. Joe has an opportunity to steal from his boss, but not much of an opportunity: he has time to steal only one of the notes. Joe now faces two and only two options. Refraining from stealing is ruled out by the threat, and Joe will satisfy the terms of the threat whichever note he steals. Both of these options still meet Timpe's criteria, inasmuch as both are (at least intuitively) objectively bad states of affairs. Whichever thing Joe does, there is a sense in which we have a bad result: a theft. Moreover, whichever option Joe picks, there is a sense in which his very action will be a morally bad thing. But moral badness is one thing, and moral wrongness is another. It is plausible in this amended case to think that Joe would not be doing anything morally wrong if he stole the twenty dollar bill. Joe would be making the best of a bad situation. And in doing that he is doing what he should be doing, namely, choosing the least bad option. Thus we can say that Joe

raise my arm for me - it doesn't seem right to say here that I raise my arm. If our intuitions are different here I suggest it's because (a) it's hard to imagine an agent ever having another person around as a reliable arm-raiser and (b) the suggested revision was in terms of a question: I am to ask the helper to raise my arm, which implies that my helper might not comply. Consider, instead, the orders given by a CEO or Field marshal; in issuing commands to their subordinates, CEOs and Field marshals will and intend certain results, and we readily say that they brought them about. 
does the right thing if he steals only the $\$ 20$ bill, and if he does the right thing, then he is praiseworthy (although perhaps only minimally)..$^{5}$ This doesn't mean that Joe's action is intrinsically good, but it doesn't have to mean that in order for the point to count against Timpe's view.

How it is with Joe is how it is with the person who becomes quiescent: the individual has two options, each of which is a bad state of affairs (compared to what it could be), but in choosing to become quiescent the agent does the right thing. Her becoming quiescent is attributable to her, and, being the right thing to do, she is praiseworthy for it. I conclude, then, that Timpe's account, if it secures the agent's control in the way designed, does not avoid Semi-Pelagianism. In the following section I will canvass two possible ways of moving forward.

\section{Moving forward: two proposals}

\subsection{Reversing the defaults}

I have argued that if we posit a prior act of will we inevitably end up with something for which the agent deserves credit. One way of potentially avoiding this problem would be to alter the default state of the agent. Suppose that instead of starting out as resisting God's offer of grace, post-Fall humans start out as quiescent. They start out with their will "turned off" with respect to God's offer. Now, because God's offer of grace is effective whenever the human person is quiescent, we cannot say that God is constantly offering his grace to everyone. That would imply that as soon as someone is born (or has the capacities required for faith), God's offer of grace will become effective and that person will come to saving faith. I take it that that is not what happens. So this part of the story needs altering. Instead, we could say that God will indeed offer his grace to each person at some point in their life. Moreover, we could suggest that he will do this after they have had some opportunity to move to a state of resisting him. If God's offer is only ever given after the agent has been given that opportunity, then the agent seems to have the required control, but at the same time we have not posited any prior act of will. Thus we can affirm that God is the only actor in the person's coming to faith, despite the fact that each person retains control over whether or not they come to faith.

Unfortunately, however, this proposal does not work. There are at least two significant theological objections. First, it is likely that someone who is motivated to provide an account which meets the Anti-Pelagian Constraint will also be motive to

\footnotetext{
${ }^{5}$ It might be objected that this conclusion relies on denying the doctrine of double effect. Double effect, if accepted, shows that someone might bring something about, and be aware of this, but yet not be responsible for doing so because she did not intend it. However, neither the above example nor the case of becoming quiescence fits with the doctrine of double effect. One key feature of the doctrine states that the unintended (but known) effect for which the agent is not responsible must not be a means to the agent's end (Mangan 1949, 43). But in both the case above and in the case of the agent who becomes quiescent, the least bad action performed is a means to the end, so double effect does not apply.
} 
retain a substantial doctrine of original sin. One worry is that this proposal does not secure such a thing. On the current proposal, the default state for a person is not a particularly good one: she does not have a will disposed towards God. But neither does she have a will configured for evil. This consequence might undermine the positive benefits of this account (were it to work).

Another theological worry concerns fairness and the problem of evil. ${ }^{6}$ If God doesn't offer each person grace straightaway, but instead has to wait until the agent has had the opportunity to move to a state of resistance, then perhaps the accumulated effect of years of both performing bad actions (unrelated to coming to faith) and being on the receiving end of bad actions might bias an individual in an unfair manner. The idea is that the individual's remaining quiescent or deciding to move to a state of resistance would become too much a function of those aspects of a person's life history which are outside of her control.

The real problem for this view, however, is that despite initial appearances it doesn't solve the problem it sets out to solve. I've talked of a person needing the opportunity to move to a state of resistance. The idea was that if the person has such an opportunity, the person is in control of and responsible for a state of affairs which obtains. There are two complications with this idea. First, not every sense of opportunity would be enough for control. There is a sense in which, in virtue of being a British citizen, Suzy has the opportunity to attend university. But circumstances might be such that Suzy cannot make use of this opportunity: she might not have the financial means, for example. Suzy could possess the one kind of opportunity, without yet being in control. Moreover, it's not that her control is undermined by some other kind of consideration - she lacks control because she lacks the right kind of opportunity. Spelling out the kind of opportunity that is required for control is difficult. But for the reasons considered above, and sticking to our current assumptions, it is plausible to think that having the right kind of opportunity will involve some kind of awareness of what one's current state is (i.e. quiescence) and that this is something one could change (i.e. one could move to a state of resistance). But then it seems that if the agent properly recognises those facts, and still continues in her state of quiescence, she has consented to her state of quiescent. This produces control, but it also re-introduces the prior act of will. So this proposal is in fact no improvement on Timpe's account whilst also incurring additional worries.

\subsection{Control over resistance without control over coming to saving faith}

Timpe's target is to secure the agent's control over whether or not she comes to saving faith $(2007,284,285,289,293)$. One way forward might be to investigate whether the agent would bear the required responsibility for her failing to come to faith if she had control over her resistance and her quiescence but lacked control over whether or not she comes to saving faith.

\footnotetext{
${ }^{6}$ I owe this point to Tasia Scrutton.
} 
It is certainly possible for an agent to control whether or not she is quiescent without being in control of whether she comes to faith. To see this, let A be the proposition that the agent accepts God's grace, $\mathrm{R}$ be the proposition that the agent resists God's grace, and $\mathrm{Q}$ be the proposition that the agent is quiescent. Now it might be thought that the agent could control $Q$ without controlling A because $Q$ and A are contraries (not contradictories): both might be false. This point does play some role but in fact things are more complicated, because it is even possible to control $\mathrm{P}$ and yet not control $\sim \mathrm{P}$. Suppose, for example, that Kate is control of a light switch which is connected in parallel to one other switch, and that both switches are connected in series to a light and power source. Let $\mathrm{P}$ be the proposition that the light is on. And suppose that the second switch is connected to a randomiser device. Then Kate controls P but she does not control $\sim$ P. ${ }^{7}$ At most, she controls whether there is a possibility of $\sim \mathrm{P}$. So control over $\mathrm{P}$ can come apart from control over $\sim \mathrm{P}$. But note that Kate has this control because she has options: she can turn her switch on or she can turn it off. This doesn't translate into the light's being on or off, but it's plausible to think that Kate's control over $\mathrm{P}$ requires her to have those options available to her.

What does this show? It suggests that an agent could control $\mathrm{R}$ even if she isn't able to bring about A, as long as she can bring about Q. That is, if the agent is in control of whether she resists God or whether she is quiescent, then whatever she does will be imputable to her and so she will be responsible for the state she realises in herself. The person's responsibility for failing to come to faith would be grounded in her ability to realise in herself a state of quiescence. We would have to insist that the person does not know her becoming quiescent would lead to her coming to faith, because if we add this knowledge then it seems to "automatically" produce in the agent the ability to come to saving faith (indirectly).

The most significant problem this idea faces is connected to the problem which I raised above for Timpe's account, namely, that the agent's becoming quiescent is the morally right action to perform. This remains the case even if we remove any possibility of the agent having control over her coming to saving faith (by removing the agent's knowledge that her becoming quiescent will lead to her saving faith). Moreover, this remains the case even if we accept that the agent's state of quiescence is an objectively bad state of affairs. The agent has two options: if she chooses the least bad option then she has done the right thing. The agent who becomes quiescent has done something for which she is praiseworthy. There is no way around this. If we deny that the agent has any knowledge of the fact that her becoming quiescent will lead to her coming to saving faith, we can deny that the latter was under her control and we can deny that she was in any way the agent of her coming to saving faith. So she won't bear any responsibility for coming to saving faith. The agent is unable to intentionally bring herself to saving faith, although she is able to do something which in fact will bring her to saving faith (it's just that she doesn't know this).

\footnotetext{
${ }^{7}$ Walton (1974) has a useful discussion of a variety of cases of this sort.
} 
Is this enough to avoid (Semi-)Pelagianism? It depends on how we read the pronouncements. Do they mean to affirm that humans are unable to perform any action with the intention that it would lead to their saving faith? Or do they make the stronger claim, namely, that humans are unable to perform any action that would in fact lead to their saving faith, whether they know it or not? If the pronouncements make the former claim but not the latter claim then the position sketched above might escape (Semi-)Pelagianism. This solution differs from Timpe's in the following way. First, it has nothing to do with the causation/quasicausation distinction. It is, I suggest, highly implausible that the solution to the problem of grace and free will could depend on such a thing, because our ordinary ascriptions of agency cut across that distinction. Second, it relies on explicitly disconnecting the agent's control over her resistance and quiescence on the one hand from her control over coming to saving faith on the other. Third, it requires us to employ a weak understanding of the pronouncements of the councils to the effect that they preclude the agent performing an action which she knows will lead to her salvation. This last point renders irrelevant the issue of whether the action which the agent does perform is morally right or not: we can accept that the agent's becoming quiescent is an action for which the agent is praiseworthy, as long as the agent doesn't conceive of what she is doing intentionally as in any way bringing about her saving faith. She's praiseworthy for something, just not coming to saving faith.

However, this proposal is not without its own problems. The weak reading of the pronouncements of the councils has some unintuitive results. Suppose that God resolves to bring to saving faith any person who picks up a purple cup at noon on the third day after a full moon. Presumably fallen human beings have the ability to pick up purple cups, and so also have the ability to pick up purple cups at noon on the $3^{\text {rd }}$ day after a full moon. On the above account they have that ability, and would come to faith were they to exercise it, only as long as they don't know what results from picking up the cup. What's puzzling here is that we would have to say that if someone came to know that her being saved would follow from her picking up the cup would, then she would lose the ability to pick up purple cups at noon on the third day of the month. Letting the acquiring of saving faith depend on a bizarre and arbitrary action - the agent's picking up a purple cup at noon on a certain day allows us to see how strange this is: the addition of knowledge has to somehow remove what looks like a predominantly physical ability. Something similar is true in the case of quiescence. On the above story, fallen humans could choose to become quiescent without any problems as long as they were blind to the fact that as a result of this they would come to faith. Any fallen human learning this would, on the current account, then lose the ability to become quiescent. This feature of the account is, at the very least, puzzling. For this reason I want to make clear that I do not mean to endorse this model, although it is, I think, the closest we can get to a solution while still positing only one unique grace. 


\section{Conclusion}

I have argued that Timpe's account of an agent's coming to faith does not avoid Semi-Pelagianism. I have suggested that Timpe's account of control is inadequate, and that fixing it will reveal that there is little basis for excluding those things agents do via quasi-causation from the scope of the Anti-Pelagian Constraint. Agents can indeed control things via quasi-causation, but that is because omissions can be imputable to them as agents, and they can, as a result, bear moral responsibility both for acting so as to bring about the omission and the omission itself. Recognising this leaves us with little reason to think that instances of agency which involve quasi-causation should be treated any differently from those which involve only causation. If we extend the Anti-Pelagian Constraint to cover such instances of agency then Timpe's account will not satisfy it.

I canvassed two possible ways forward. I explored the possibility of reversing the defaults such that the agent starts out quiescent but has the opportunity to move to a state of resistance. This introduced two theological worries and didn't, in the end, solve the underlying philosophical problem. A more promising approach limited the agent's control such that she did not have control over her coming to saving faith but did control whether she resisted or was quiescent (this required denying that the agent knows her becoming quiescent would lead to her coming to faith). I suggested that this proposal is the closest we can get to a solution while positing only one unique grace (other ways forward, not discussed here, might involve positing more than one unique grace). But still problems remain. The person who becomes quiescent does the morally right thing and so is praiseworthy for that act. I suggested that whether or not this constitutes a serious objection depends on the particular understanding of the condemnations of (Semi-)Pelagianism that we employ. However, if we employ a reading according to which the proposal avoids Semi-Pelagianism, the resulting view has some unintuitive consequences concerning the agent's abilities. In closing, it seems that one grace solutions (two grace solutions, if we count the grace of creation) do not fare well when it comes to securing the agent's responsibility for lack of faith while at the same time avoiding (Semi-)Pelagianism. ${ }^{8}$

\section{References}

Dowe, Phil. 2001. “A Counterfactual Theory of Prevention and 'Causation' by Omission." Australasian Journal of Philosophy 79 (2): 216-26.

Mangan, Joseph. 1949. "An Historical Analysis of the Principle of Double Effect." Theological Studies 10: 41-61.

${ }^{8}$ I would like to thank audiences at the Centre for Philosophy of Religion at the University of Leeds, and at the Analytic Theology Summer School at the Universität Innsbruck, for probing questions and helpful comments. Special thanks also go to Kevin Timpe and Leigh Vicens for very helpful discussion. 
Pohle, J. 1917a. "Pelagius and Pelagianism." In The Catholic Encyclopedia. Vol. 11, ed. Kevin Knight. New York: Robert Appleton Company. http://www.newadvent.org/cathen/11604a.htm.

———. 1917b. "Semipelagianism." In The Catholic Encyclopedia. Vol. 13, ed. Kevin Knight. New York: Robert Appleton Company.

Ragland, C. P. 2006. "The Trouble with Quiescence: Stump on Grace and Freedom." Philosophia Christi 8 (2): 343-62.

Schaff, Philip. Nicene and Post-Nicene Fathers: Second Series. Volume 14: The Seven Ecumenical Councils. Grand Rapids, Michigan: William B. Eerdmans Publishing Company.

Schaffer, Jonathan. 2012. “Disconnection and responsibility.” Legal Theory 18 (04): 399-435. doi: 10.1017/S1352325212000092.

Stump, Eleonore. 2003. Aquinas. London,, New York: Routledge.

- - . 2007. "Justifying faith, free will, and the Atonement." In Freedom and the human person, 90-105. Studies in philosophy and the history of philosophy v. 48. Washington, D.C: Catholic University of America Press.

Timpe, Kevin. 2007. "Grace and controlling what we do not cause." Faith and Philosophy 24 (3).

Walton, Douglas N. 1974. "Control." Behaviorism 2: 162-71. 